\title{
Investigation of the Treadport for Gait Rehabilitation of Spinal Cord Injury
}

\author{
Babak Hejrati, Dale Hull, Jan Black, Jake J. Abbott, and John M. Hollerbach
}

\begin{abstract}
The goal of this study is to compare the effect of training by the University of Utah's Treadport versus a conventional treadmill on gait improvement of spinal-cord-injury (SCI) patients. Four incomplete SCI subjects who had reached a rehabilitation plateau were selected to have training first on the treadmill and then the Treadport. Spatiotemporal and gait parameters were utilized to make a comparison between the two training conditions. Overall, the results demonstrated statically significant improvements in most of the spatiotemporal as well as some of the gait parameters during training with the Treadport relative to the traditional treadmill.
\end{abstract}

\section{INTRODUCTION}

In recent years there has been a trend in locomotion training of spinal cord injury (SCI) where body-weight-supported treadmills are utilized for treating gait impairments [6] and are considered as the gold standard in gait rehabilitation [12]. The advantages of using a treadmill for neurorehabilitation include adequate mobility of the patient despite the small area occupied by the treadmill, partial weight support, "optimal" control of the experimental environment, and simple use of monitoring equipment [14].

Since the ultimate goal of rehabilitation is to prepare patients for overground walking, a substantial amount of research has been done to compare treadmill walking versus overground walking. Alton et al. [1] found no significant differences in joint kinematics and temporal parameters between treadmill and overground walking. In addition to kinematics, Murray et al. [17] used electromyography (EMG) signals and heart rate to show the similarity of the two conditions. Using kinematic and EMG gait patterns at different walking speed, Nymark et al. [18] also concluded that there are minimal differences between the conditions. Riley et al. [22] showed that the major difference lies in the ground reaction forces, where maximum ground reaction forces were significantly smaller for the treadmill walking. Lee and Hidler [14] stated that, from a therapeutic perspective, the overall kinematic and muscle activation patterns seem to be similar enough to justify use of treadmills for training stroke and SCI patients.

As the result of similarity between overground and treadmill walking, body-weight-supported treadmill training (BWSTT) is a widely accepted method for rehabilitation of

The project described was supported in part by Award Number UL1RR025764 from the National Center for Research Resources and from the office of the Vice President for Research at the University of Utah.

B. Hejrati and J. J. Abbott are with the Department of Mechanical Engineering, University of Utah, Salt Lake City, UT 84112 babak. hejratiautah. edu

Dale Hull and Jan Black are with Neuroworx, Sandy, UT 84095

J. M. Hollerbach is with the School of Computing, University of Utah, Salt Lake City, UT 84112 jmh@ cs. utah. edu

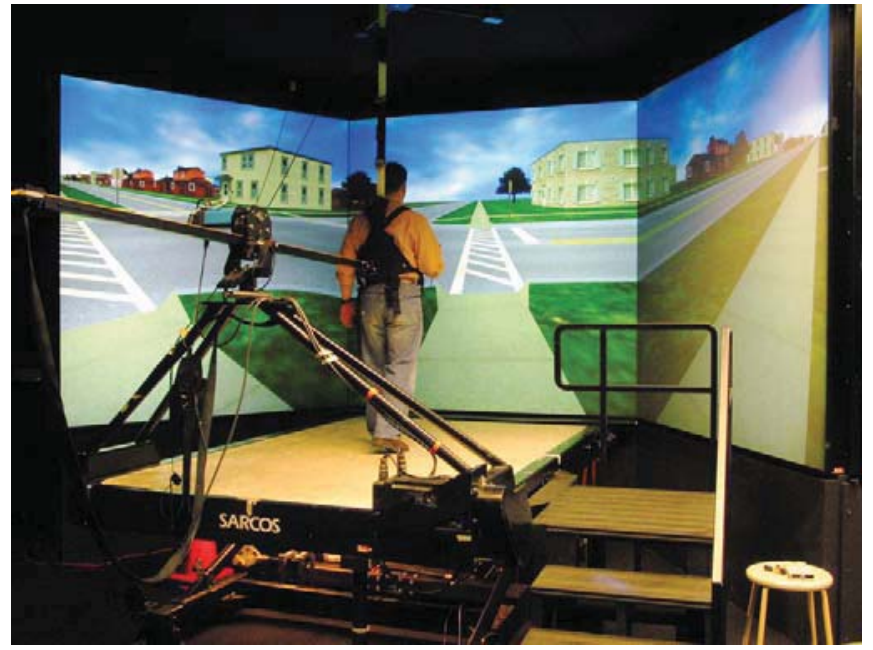

Fig. 1: Treadport virtual environment comprising a CAVElike visual display and locomotion interface. This image, shown for clarity, was taken before the addition of the active wind tunnel and Vicon motion capturing system.

SCI and post-stroke patients. Dietz et al. [4] implemented partial weight support on a moving treadmill and observed a significant increase in the amplitude of EMG signals of the patients' disabled legs with complete paraplegia. Dobkin et al. [7] obtained a locomotor-like EMG activity in the subjects without supraspinal descending influence when optimal sensory inputs were applied to them during rehabilitation with a treadmill. Furthermore, Dietz and Harkeman [5] highlighted the effectiveness of providing appropriate sensory cues for SCI patients during BWSTT.

Wernig et al. [26] reported overall improvements in balance, walking speed, and covered distance of their SCI subjects after training on a commercial motor-driven treadmill (Laufband) with a variable speed control and a supporting harness. In addition, robotic systems such as Lokomat [20], [21], LOPES [25], and WalkTrainer [24] have become increasingly common in gait rehabilitation. In summary, strong evidence implies that BWSTT has significant potential to produce physical and psychological improvements in SCI patients [8].

The University of Utah Treadport (Figure. 1) is a large tilting-linear-platform locomotion interface that has been designed to provide advanced multisensory and mechanical cues. It is comprised of an active mechanical tether attached to the user through a body harness, a CAVE-like visual display, a motorized winch for partial body-weight support, a passive safety tether, and an active wind tunnel 
[10], [13], [11]. The six-axis mechanical tether measures body position and orientation for active control of the belt speed and for updating the graphics. Missing in conventional treadmills, the Treadport lets the user select his/her speed by velocity controller proportional to users' displacement rather than manually, which is crucial in simulating real walking condition. This ability to naturally adjust walking speed also results in an improved sense of safety, since the user need not fear the prospect of not being able to keep up with a moving belt; slowing down is as natural on the Treadport as it is in natural walking. In addition, the belt's dimension $(2 \mathrm{~m} \times 1.8 \mathrm{~m})$ provides the user with a large area such that he/she can easily explore the virtual environment without fear of stepping off. Visual cues provided by three displays simulate different environments including, but not limited to, a mountainous terrain and a cityscape. The screens are highly diffuse acrylic back-projection screens, and three HughesJVC G1000 SXGA projectors create the graphical images.

Although the Treadport is designed for a variety of applications, its key features are particularly suitable for SCI rehabilitation. The objective of this study was to perform an initial investigation of the Treadport as a tool for gait rehabilitation of SCI patients. We hypothesized that using the Treadport instead of a treadmill could lead to better clinical outcomes in terms of spatiotemporal parameters, kinematic parameters, and gait symmetry. Furthermore, that the Treadport would provide an increased sense of safety, comfort, and flexibility for SCI patients, which would in turn enable them to exploit their potential. In addition, exploring the virtual environment requires them to keep their head upright and maintain a proper upper-body posture, which is usually missing in training with traditional treadmills. Repeated measure ANOVA was utilized to compare gait data between the walking conditions for four subjects. The results of this preliminary study indicate that training on the Treadport led to statistically significant improvement in most of the gait parameters of interest compared to a traditional treadmill.

\section{METHODS}

\section{A. Subjects}

We selected four subjects (three males and one female) with incomplete SCI as being good candidates for these preliminary studies. The inclusion criteria were that they were currently undergoing rehabilitation at Neuroworx (Sandy, UT) and they were able to ambulate independently over ground, with or without an assistive device. The exclusion criteria included inadequate range of motion, joint contracture affecting functional mobility, poor joint integrity, diminished bone density, and compromised balance. Subjects were medically stable as indicated by physician evaluation. Participants were chosen to represent a range of SCI individuals who may potentially benefit from training on the Treadport. Table I presents the subjects' information. One of the subjects (Subject 3) sometimes uses canes for assistance, but did not during experiments. Subject 4 usually uses a wheelchair, but he can walk on the Treadport and a treadmill
TABLE I: Subjects' information

\begin{tabular}{ccccccc}
\hline \hline Subject & Gender & $\begin{array}{c}\text { Age } \\
\text { (years) }\end{array}$ & $\begin{array}{c}\text { Weight } \\
(\mathrm{kg})\end{array}$ & $\begin{array}{c}\text { Height } \\
(\mathrm{cm})\end{array}$ & $\begin{array}{c}\text { Injury } \\
\text { type }\end{array}$ & $\begin{array}{c}\text { Rehab } \\
\text { Duration } \\
\text { (years) }\end{array}$ \\
\hline 1 & female & 15 & 55 & 165 & T-9 & 1 \\
2 & male & 24 & 58 & 165 & L-1 & 1 \\
3 & male & 56 & 76 & 178 & C-4,5 & 4 \\
4 & male & 69 & 87 & 180 & C-5 & 5 \\
\hline
\end{tabular}

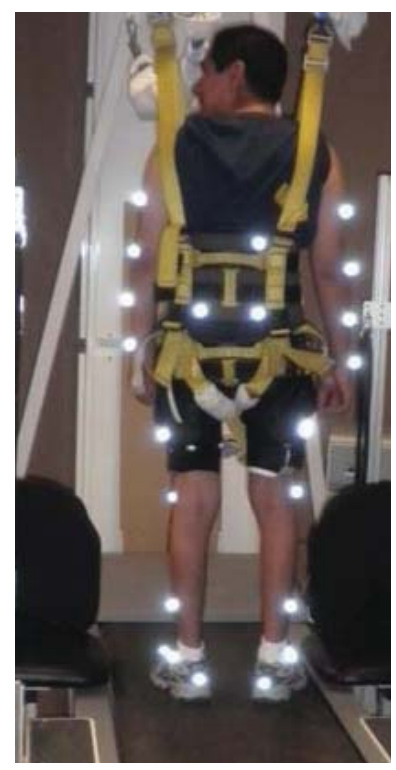

(a)

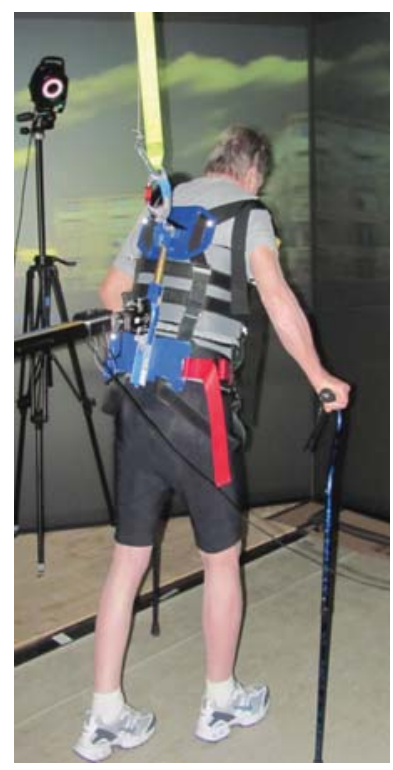

(b)
Fig. 2: (a) Subject 2 on the treadmill at Neuroworx, (b) Subject 4 on the Treadport at the University of Utah

using canes. Each subject was given a consent form approved by the University of Utah Institution Review Board, and for one of the subjects, who was 15 years old, her parents signed a parental permission and authorization document.

\section{B. Experimental protocol}

Two experimental conditions were designed for the study. In the first condition, subjects spent six sessions of twenty minutes training on the treadmill at Neuroworx while a physical therapist was present to directly supervise them. The six sessions were spread out evenly over three weeks. The speed of the treadmill was adjusted for each individual subject based on his/her preference at the onset of each session and kept constant during the session. Partial body weight support was provided for each subject by a hydraulicpump-actuated winch. At the sixth training session on the treadmill, kinematic and spatiotemporal gait parameters were measured by a VICON (Oxford, UK) motion capturing system. Before starting the second set of experiment, a two month delay was applied to minimize any carryover effect from the treadmill to Treadport.

The second set of experiments was carried out on the Treadport at the University of Utah. Similar to the training sessions on the treadmill, each subject spent six twentyminute training sessions spread out evenly over three weeks. 
Subjects walked through a virtual cityscape while a horizontal tether, safety tether, and weight-support tether were attached to them via a rehabilitation-style harness depicted in Figure. 2. A safety switch was kept pressed during training by the physician or experimenter to shut off the system as soon as the subject encountered any difficulties. Partial bodyweight support was provided by means of a motorized winch hanging from the Treadport's room ceiling. The subject's weight was used to set the initial value for the weight parameter in the Treadport control algorithm. The weight parameter determines the force exerted by the horizontal tether on the subject to simulate inertia force as the belt accelerates. The initial value of the weight parameter for each subject was manually modified slightly during his/her first session to find a proper value according to the subject's comfort. This value was then maintained for all six trials.

In both the treadmill and Treadport experiments, the subjects were instructed to walk as fast as they were comfortable with. In the case of the Treadport, the subjects set their speed as they would during normal walking. In the case of the treadmill, the subjects verbally instructed the physical therapist to adjust the speed of the treadmill.

\section{Data collection}

Gait kinematics and spatiotemporal parameters were recorded by the VICON motion capturing system, comprised of six cameras located around a calibrated volume. Cameras had a sampling frequency of $200 \mathrm{~Hz}$ and high accuracy to detect the position of 9-mm-diameter markers on the subjects' skin as depicted in Figure. 2. Motion capturing sessions were independent sessions on different days after accomplishing six sessions of training. Motion capturing started after letting subjects walk for six minutes to reach their steady state on both the treadmill and the Treadport. We captured five trials per subject including at least five gait cycles for each subject.

\section{DATA POST PROCESSING}

\section{A. Joint angles}

Kinematic variables are thought to be the best control variables for gait analysis [14]. Since major changes in the joint angles occur in the sagittal plane, we decided to choose the hip and knee joint angles for our study. Due to the visibility constraints imposed by wearing the harness, and also not using any cameras in front of the subjects because of the screens, we did not use the default gait model of the VICON system for motion capturing. On each body segment including torso, femurs, tibia, and foot, we used retro-reflector markers to define them as rigid bodies and then we defined a unit vector in 3D space for each segment. The dot product of two adjacent vectors was taken to evaluate the cosine of joint angles between segments.

\section{B. Spatiotemporal parameters}

Spatiotemporal and timing parameters are of high importance for gait analysis since they reveal more details about the patient's gait and can help us to compare our

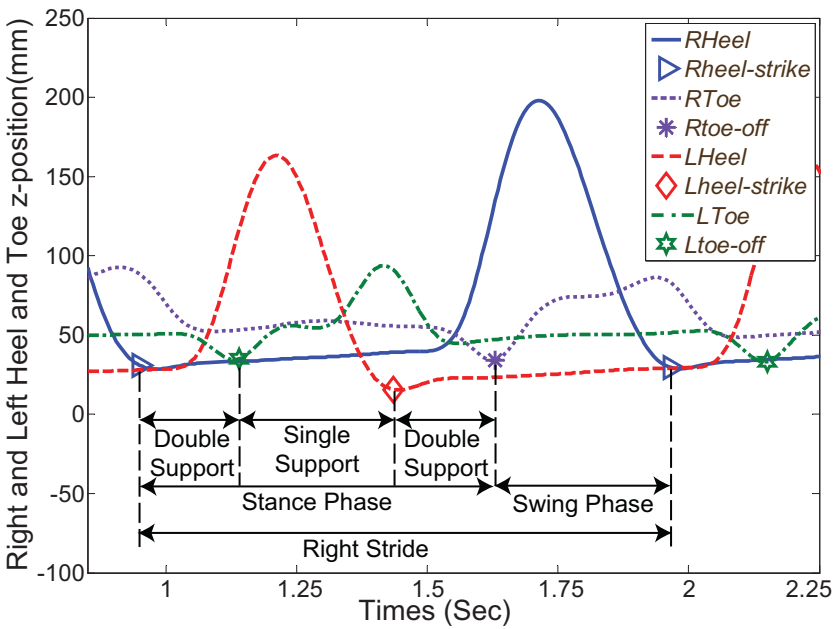

Fig. 3: Phases in a right stride cycle (Subject 2)

two walking conditions more comprehensively. The most important events during the gait cycle are heel-strikes and toe-offs, by which all other parameters are defined (Figure. 3). Usually, visual inspection of heel and toe markers' trajectories is carried out to detect heel-strikes and toeoffs. However, some researchers have recently proposed new methods to automatically detect these events and evaluate spatiotemporal parameters [16], [2]. To account for subjects' various heights, the three parameters speed, cadence, and stride length were normalized using the procedures in [14] which yields the normalized speed $\widetilde{S}$, cadence $\widetilde{C}$, and stride length $\widetilde{L}_{\text {stride }}$ :

$$
\begin{aligned}
& \widetilde{S}=\frac{S}{\sqrt{h \cdot g}} \\
& \widetilde{C}=C \sqrt{\frac{h}{g}} \\
& \widetilde{L}_{\text {stride }}=\frac{L_{\text {stride }}}{h}
\end{aligned}
$$

where $h$ is the subject's height in meters, and $g$ is gravity $\left(9.81 \mathrm{~m} / \mathrm{s}^{2}\right)$.

\section{Symmetry}

Symmetry in contralateral joint angles is a characteristic of normal walking. Both legs should repeat almost an identical motion with a phase shift due to the opposite motion of the legs. The correlation coefficient between right and left joint angles was calculated to show the linear dependence between the two signals. First, the signals were synchronized by performing the phase shift before analysis. Figure. 4 demonstrates the signals before and after synchronization. The correlation coefficient $\rho_{x y}$ was then calculated from [3].

$$
\rho_{x y}(\tau)=\frac{C_{x y}(\tau)}{\sqrt{C_{x x}(0) C_{y y}(0)}}
$$

where $x$ and $y$ are right and left joint angles, $C_{x y}$ and $C_{x x}$ are cross and auto correlations respectively, and $\tau$ is the time delay between two signals (right and left feet's markers). 

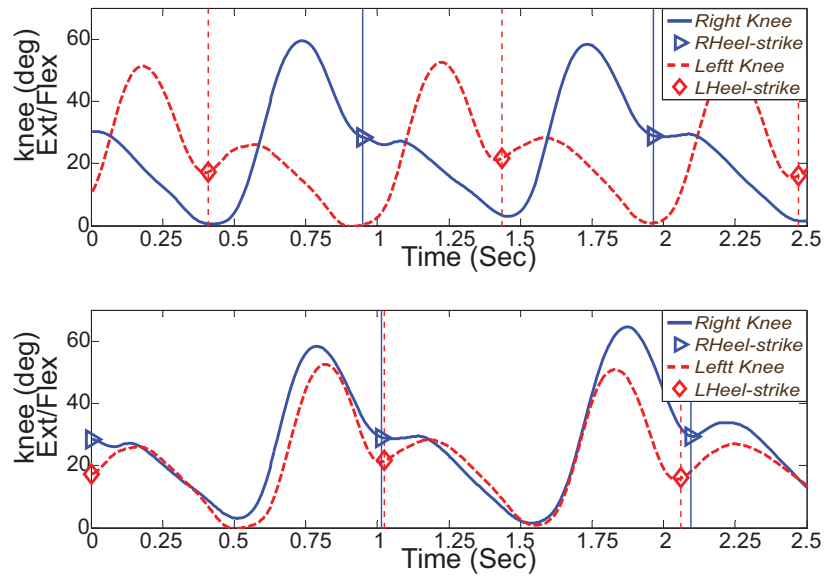

Fig. 4: Right and left joint angles for Subject 2 (top) before synchronization and (bottom) after synchronization.

\section{RESULTS}

To evaluate the effect of training on the Treadport compared to a traditional treadmill, we used kinematic, spatiotemporal, and symmetry parameters. For kinematic parameters, the range of motion (ROM) of hip and knee joint angles are presented in Table II, and Table III presents the spatiotemporal parameters. In both tables, normal values for human gait have been presented for comparison. Both legs' parameters are illustrated and evaluated separately to account for the asymmetric ambulation of subjects. The Shapiro-Wilk test [23] of normality was performed on the collected data, however ANOVA is robust to this assumption.

In Table II and III, a (+) superscript indicates a statistically significant improvement in the Treadport compared to the treadmill for a given parameter, whereas a $(-)$ denotes a statistically significant decline. For those parameters that do not have any superscripts, no statistically significant changes were observed.

A normal range of motion for the knee joint during walking is within the full range of flexion of $0^{\circ}-65^{\circ}\left(70^{\circ}\right)$, and a normal range of motion of the hip joint is within $10^{\circ}$ of extension and $30^{\circ}$ of flexion [14], [19], [15]. In Table II, a statistically significant change toward the normal range of motion is considered an improvement.

Spatiotemporal analysis has an advantage that its techniques are standardized and reasonably reliable. Improvements in spatiotemporal parameters also correlate with improvements in a person's functional ambulation. For the spatiotemporal parameters - normalized stride, normalized cadence, normalized speed, and step length - an increase is considered an improvement [9]. In healthy human walking, the percentage of the gait cycle devoted to the swing phase is approximately $40 \%$ and the percentage of stance phase time is $60 \%$; approaching these two values for swing and stance times is desired. The same analogy can be applied to single support and double support time, where approaching $40 \%$ and 20\%, respectively, is sought [19], [15] (Table III).
The correlation coefficient indicates how much the right and left joint signals are similar to each other, where $\rho=1$ stands for perfect symmetry in walking (Table IV).

Since subjects differed in terms of medical conditions and the nature of their injuries, we performed ANOVA within a given subject, rather than across subjects, to quantify any improvement or decline when walking in the Treadport relative to walking on the treadmill. The following summarizes the results of each subject, including their own responses to our questionnaire.

Subject 1 was a teenaged female with a T-9 injury. She demonstrated a significant improvement in 10 of 14 spatiotemporal parameters considered, and no significant declines. She demonstrated a large improvement in hip symmetry, and of all of the subjects tested, she demonstrated the most improvement in joint ROM. Subject 1 said "I liked the life-like pictures...but would have liked it if it was a little more like outdoors." and "I liked how wide the Treadport was. It made me less nervous where my feet were because there was more room. I was not worried about falling off if I made a mistake."

Subject 2 was a young man with an L-1 injury. Although results for joint ROM were mixed, he showed a significant improvement in 5 of 14 spatiotemporal parameters. He also, showed a large improvement in both hip and knee symmetry. Subject 2 felt that the Treadport, compared to normal walking, "provides resistance and helps to strengthen leg muscles." He said "Screen projections provide the feeling of direction and movement as opposed to treadmill walking in the same place."

Subject 3 was a middle-aged man with C-4,5 spinal cord injury. Results for joint ROM were mixed. Significant improvements were observed in all of his spatiotemporal parameters. His timing pattern converged to what is considered a normal pattern in the literature. He also developed a more symmetric hip movement. Subject 3 also felt comfortable attempting to jog on the Treadport, which he had never done on a treadmill.

Subject 4 was an elderly man with a C-5 spinal cord injury. He had to use his canes during walking on both the treadmill and Treadport and needed the most amount of weight support compared to other subjects (more than $11 \mathrm{Kg}$ ). Due to his condition, analyzing his data is complicated and, to some extent, inconclusive. Although there were significant positive changes in 7 of 14 of his spatiotemporal and timing parameters, his symmetry indices deteriorated dramatically. Subject 4 said "I found it better to use my canes because it is so much wider than the normal treadmill. It is also nice to have scenery on three sides. I can see a real advantage of being able to move sideways, go up and down the hills, even though my ability didn't enable me to do that very well. I could say that it was harder for me because I had to propel it. But, it is more like walking. I think it could be a real advantage for people like me." 
TABLE II: Joint range for hip and knee (degrees) in sagittal plane for treadmill and Treadport walking. Data given as Mean(Standard Deviation). A + symbol indicates a statistically significant $(p<0.05)$ improvement in the Treadport vs. the treadmill. A - symbol indicates a statistically significant decline.

\begin{tabular}{ccccccc}
\hline \hline \multirow{2}{*}{ Subject } & & \multicolumn{2}{c}{ Treadmill } & \multicolumn{2}{c}{ Treadport } \\
\cline { 3 - 7 } & Parameter & Ideal values & Left & Right & Left & Right \\
\hline \multirow{2}{*}{1} & Hip & 40 & $28.92(2.25)$ & $22.95(1.42)$ & $30.8(3.5)$ & $28.87(1.85)^{+}$ \\
& Knee & 65 & $42.87(1.61)$ & $56.85(0.63)$ & $48.1(3.1)^{+}$ & $53.74(2.5)$ \\
\hline \multirow{2}{*}{2} & Hip & 40 & $22.47(1.67)$ & $25.33(1.62)$ & $27.6(1.33)$ & $25.38(0.85)$ \\
& Knee & 65 & $42.16(2.72)$ & $66.19(3.63)$ & $50.08(2.42)^{+}$ & $59.12(2.95)$ \\
\hline \multirow{2}{*}{3} & Hip & 40 & $28.33(0.47)$ & $28.09(0.01)$ & $25.85(0.78)^{-}$ & $24.27(0.94)^{-}$ \\
& Knee & 65 & $54.3(0.83)$ & $45.17(0.1)$ & $59.04(1.04)^{+}$ & $51.97(1.57)^{+}$ \\
\hline & Hip & 40 & $19.44(0.57)$ & $17.80(0.2)$ & $21.22(2.48)$ & $17.23(1.32)$ \\
& Knee & 65 & $32.47(1.0)$ & $19.57(1.12)$ & $36.36(2.71)$ & $22.19(2.48)$ \\
\hline
\end{tabular}

TABLE III: Spatiotemporal gait parameters for treadmill and Treadport walking. Data given as Mean(Standard Deviation). A + symbol indicates a statistically significant improvement $(p<0.05)$ in the Treadport vs. the treadmill. A - symbol indicates a statistically significant decline.

\begin{tabular}{|c|c|c|c|c|c|c|}
\hline \multirow[b]{2}{*}{ Subject } & \multirow[b]{2}{*}{ Parameter } & \multirow[b]{2}{*}{ Ideal values } & \multicolumn{2}{|c|}{ Treadmill } & \multicolumn{2}{|c|}{ Treadport } \\
\hline & & & Left & Right & Left & Right \\
\hline \multirow{7}{*}{1} & Normalized Stride Length & $0.71-0.73$ & $0.36(0.01)$ & $0.34(0.01)$ & $0.45(0.02)^{+}$ & $0.45(0.02)^{+}$ \\
\hline & Normalized Speed & $0.27-0.28$ & $0.11(0.01)$ & $0.10(0.01)$ & $0.15(0.04)^{+}$ & $0.15(0.02)^{+}$ \\
\hline & Normalized Cadence & $45-47$ & $38.47(0.73)$ & $35.81(1.89)$ & $40.74(1.66)$ & $42.27(0.75)^{+}$ \\
\hline & Stance Phase (\%) & 60 & $66.57(1.6)$ & $67.81(1.1)$ & $63.1(1.5)^{+}$ & $64.8(2.5)$ \\
\hline & Swing Phase $(\%)$ & 40 & $33.43(1.6)$ & $32.19(0.01)$ & $36.9(1.5)^{+}$ & $35.2(2.5)$ \\
\hline & Single Support Phase (\%) & 40 & $32.27(0.8)$ & $33.03(0.5)$ & $35.5(2.3)$ & $36.6(1.3)^{+}$ \\
\hline & Double Support Phase (\%) & 20 & $34.3(2.18)$ & $34.78(1.45)$ & $27.6(2.5)^{+}$ & $28.87(3.1)^{+}$ \\
\hline \multirow{7}{*}{2} & Normalized Stride Length & $0.71-0.73$ & $0.41(0.01)$ & $0.37(0.01)$ & $0.43(0.02)$ & $0.41(0.024)^{+}$ \\
\hline & Normalized Speed & $0.27-0.28$ & $0.15(0.03)$ & $0.14(0.01)$ & $0.17(0.01)^{+}$ & $0.16(0.01)^{+}$ \\
\hline & Normalized Cadence & $45-47$ & $46.02(2.10)$ & $44.09(2.66)$ & $48.31(1.53)$ & $45.96(1.89)$ \\
\hline & Stance Phase (\%) & 60 & $68.2(1.8)$ & $66.8(1.5)$ & $67.7(0.9)$ & $65.1(0.9)^{+}$ \\
\hline & Swing phase $(\%)$ & 40 & $32(1.8)$ & $33.2(1.5)$ & $32.3(0.9)$ & $35.1(0.9)$ \\
\hline & Single Support Phase (\%) & 40 & $33.1(0.8)$ & $32.3(1.7)$ & $34.9(0.8)$ & $32.2(0.3)$ \\
\hline & Double Support Phase (\%) & 20 & $34.9(1.8)$ & $34.4(2.5)$ & $32.8(1.1)^{+}$ & $32.8(0.8)$ \\
\hline \multirow{7}{*}{3} & Normalized Stride Length & $0.71-0.73$ & $0.61(0.00)$ & $0.63(0.00)$ & $0.69(0.01)^{+}$ & $0.69(0.01)^{+}$ \\
\hline & Normalized Speed & $0.27-0.28$ & $0.17(0.00)$ & $0.17(0.12)$ & $0.24(0.00)^{+}$ & $0.24(0.00)^{+}$ \\
\hline & Normalized Cadence & $45-47$ & $33.43(0.61)$ & $34.32(0.06)$ & $42.74(0.77)^{+}$ & $42.19(1.03)^{+}$ \\
\hline & Stance Phase (\%) & 60 & $63.9(1.3)$ & $61.2(0.1)$ & $63.2(0.6)^{+}$ & $60.1(0.6)^{+}$ \\
\hline & Swing Phase $(\%)$ & 40 & $36.1(1.3)$ & $38.8(0.1)$ & $37.2(0.6)^{+}$ & $39.4(0.6)^{+}$ \\
\hline & Single Support Phase (\%) & 40 & $38.1(1.8)$ & $35.5(0.7)$ & $39.6(0.9)^{+}$ & $37.3(0.1)^{+}$ \\
\hline & Double Support Phase (\%) & 20 & $25.8(1.31)$ & $25.7(0.7)$ & $23.4(1.2)^{+}$ & $23.3(1.6)^{+}$ \\
\hline \multirow{7}{*}{4} & Normalized Stride Length & $0.71-0.73$ & $0.34(0.03)$ & $0.34(0.02)$ & $0.32(0.04)$ & $0.37(0.01)^{+}$ \\
\hline & Normalized Speed & $0.27-0.28$ & $0.03(0.02)$ & $0.03(0.02)$ & $0.04(0.01)$ & $0.05(0.02)^{+}$ \\
\hline & Normalized Cadence & $45-47$ & $13.25(0.29)$ & $13.32(0.15)$ & $15.92(0.88)^{+}$ & $21.2(2.83)^{+}$ \\
\hline & Stance Phase (\%) & 60 & $78.6(2.4)$ & $84.7(0.5)$ & $77.6(1.9)$ & $80.4(0.1)^{+}$ \\
\hline & Swing Phase (\%) & 40 & $21.4(2.4)$ & $15.3(0.8)$ & $22.4(1.9)$ & $19.6(0.1)^{+}$ \\
\hline & Single Support Phase (\%) & 40 & $18.2(3.8)$ & $22.3(1.2)$ & $20.1(0.06)$ & $20.2(0.01)^{-}-$ \\
\hline & Double Support Phase (\%) & 20 & $60.4(6.2)$ & $62.4(0.9)$ & $57.5(1.9)$ & $60.3(0.01)^{+}$ \\
\hline
\end{tabular}

TABLE IV: Correlation coefficient $\rho_{x y}$ for treadmill and Treadport walking

\begin{tabular}{ccccc}
\hline \hline \multirow{2}{*}{ Subject } & \multicolumn{2}{c}{ Hip } & \multicolumn{2}{c}{ Knee } \\
\cline { 2 - 5 } & Treadmill & Treadport & Treadmill & Treadport \\
\hline 1 & 0.76 & 0.91 & 0.89 & 0.89 \\
2 & 0.61 & 0.95 & 0.82 & 0.94 \\
3 & 0.64 & 0.80 & 0.97 & 0.97 \\
4 & 0.91 & 0.25 & 0.85 & 0.57 \\
\hline
\end{tabular}

\section{DISCUSSIONS}

In this article, we presented the results of our preliminary study for investigation of the University of Utah Treadport for gait rehabilitation. We hypothesized that training on the Treadport has potential benefits for spinal cord injury, stemming from its virtual outdoor environment, large treadmill size, and self-directed motion. We compared locomotion training on the Treadport to training on a standard rehabilitation treadmill. Four partial-SCI patients were chosen as good candidates for the studies. Kinematic parameters, spatiotemporal parameters, and symmetry indices were utilized as metrics for making a comprehensive comparison. To carry out the gait measurements, a VICON motion capturing system was utilized. An algorithm was proposed for detecting the key gait events during ambulation on the treadmill and the Treadport in the absence of force plates.

The results of this preliminary study indicate that walking in the Treadport has significant benefits relative to walking on a treadmill, across subjects, in terms of the majority of spatiotemporal parameters considered. The study indicates that patients choose to walk faster on the Treadport than on 
a treadmill, possibly due to an increased sense of safety or due to the motivation provided by the virtual environment. The Treadport also improved gait symmetry in three of four subjects, likely due to the gait being patient driven rather than treadmill driven. The fourth subject, for whom gait symmetry actually declined, was the only subject to use canes during the experiments, indicating that rehabilitation in the Treadport may not be appropriate for certain patients. However, this fourth subject did see a net improvement in spatiotemporal parameters, so results for this subject are somewhat inconclusive. When comparing hip and knee joint range of motion with the treadmill and Treadport, results are mixed, and one system does not appear clearly better than the other. However, as presented in Table II, joint ranges of right and left legs for all the subjects, except for Subject 4 , had become more similar by the end of training on the Treadport.

The outcome of this preliminary study would imply that standard treadmills may impose some constrains on a patient's motion that can be overcome on the Treadport. Since the goal of gait rehabilitation is to prepare patients for real-world walking, training should closely simulate realworld conditions. Three major avenues that can be explored by means of the Treadport are the use of different virtual environments to influence and encourage the patients, the application of perturbations to enhance motor learning, and therapy that adapts to the patient's performance in real time.

\section{ACKNOWLEDGMENT}

We would like to thank Dr. Mark Minor for his technical contributions and Kyle Crandall and Erin Parsons for their assistance in data collection. We would also like to thank Dr. Daniel Ferris from the University of Michigan for his helpful suggestions.

\section{REFERENCES}

[1] F. Alton, L. Baldey, S. Caplan, and M. Morrissey, "A kinematic comparison of overground and treadmill walking," Clinical Biomechanics, vol. 13, no. 6, pp. 434-440, 1998.

[2] J. Bae, K. Kong, N. Byl, and M. Tomizuka, "A mobile gait monitoring system for gait analysis," in IEEE Int. Conf. Rehabilitation Robotics, 2009.

[3] J. S. Bendat and A. G. Piersol, Engineering Application of Correlation And Spectral Analysis. John Wiley and Sons, Inc, 1980.

[4] V. Dietz, G. Colombo, L. Jensen, and L. Baumgartner, "Locomotion capacity of spinal cord in paraplegic patients," Ann Neurol, vol. 37, pp. 574-582, 1995.

[5] V. Dietz and S. Harkeman, "Locomotor activity in spinal cord-injury persons," J. Applied Physiology, vol. 96, pp. 1954-1960, 2004.

[6] B. Dobkin, D. Apple, H. Barbeau, M. Basso, A. Behrman, D. Deforge, J. Ditunno, G. Dudley, and R. Elashoff, "Methods for a randomized trial of weight-supported treadmill training versus conventional training for walking during inpatient rehabilitation after incomplete traumatic spinal cord injury," J. Neurorehabilitation and Neural Repair, vol. 17, pp. 153-167, 2003.

[7] B. Dobkin, S. Harkema, P. Requejo, and V. Edgerton, "Modulation of locomotor-like emg activity subjects with complete and incomplete spinal cord injury," J. Neurological Rehabilitation, vol. 9, pp. 183-190, 1995.

[8] A. Hicks, "Treadmill training after spinal cord injury: It is not just about the walking," J. Rehabilitation Research and Development, vol. 45, no. 2, pp. 241-248, 2007.
[9] M. K. Holden, K. M. Gill, and M. R. Magliozzi, "Clinical gait assessment in the neurologically impaired: Reliability and meaningfulness," Physical Therapy, vol. 64, pp. 34-40, 1984.

[10] J. M. Hollerbach, R. Mills, D. Tristano, R. R. Christensen, W. B. Thompson, and Y. Xu, "Torso force feedback realistically simulates slope on treadmill-style locomotion interfaces," Int. J. Robotics Research, vol. 20, no. 12, pp. 939-952, 2001.

[11] J. M. Hollerbach, Y. Xu, R. R. Christensen, and S. C. Jacobsen, "Design Specifications for the second generation SARCOS Treadport locomotion interface," in Haptics Symposium, Proc. ASME Dynamic Systems and Control Division, 2000.

[12] A. Koenig, X. Omlin, J. Bergmann, L. Zimmerli, M. Bolliger, F. Muller, and R. Riener, "Controlling patient participation during robot-assisted gait training," J. NeuroEngineering and Rehabilitation, vol. 8, pp. 8-14, 2011.

[13] S. D. Kulkarni, M. A. Minor, M. W. Deaver, E. R. Pardyjak, and J. M. Hollerbach, "Steady headwind display with conditional angular rate-switching control," in IEEE Int. Conf. Robotics and Automation, 2008.

[14] S. J. Lee and J. Hidler, "Biomechanics of overground vs. treadmill walking in healthy individuals," J. Applied Physiology, vol. 104, no. 3, pp. 747-755, 2008.

[15] J. F. Lehmann, B. J. deLateur, and R. Price, "Biomechanics of normal gait," Phys Med Rahabil Clin North Am, vol. 3, pp. 125-138, 1992.

[16] P. Lopez-Meyer, E. Sazonov, and G. Fulk, "Automatic detection of temporal gait parameters in post-stroke individuals," IEEE Trans. Information Technology in Biomedicine, vol. 99, pp. 594-601, 2011.

[17] M. P. Murray, G. B. Spurr, S. B. Sepic, G. M. Gardner, and L. A. Mollinger, "Treadmill vs. floor walking: kinematics, electromyogram, and heart rate," J. Applied Physiology, vol. 59, no. 1, pp. 87-91, 1985.

[18] J. R. Nymark, S. J. Balmer, E. H. Melis, E. D. Lemaire, and S. Millar, "Electromyographic and kinematic nondisabled gait differences at extremely slow overground and treadmill walking speeds," J. Rehabilitation Research and Development, vol. 42, no. 4, pp. 523-534, 2005.

[19] J. Perry, Gait Analysis. Thorofare, NJ: SLACK Incorporated, 1992.

[20] R. Riener, L. Lunenburger, S. Jezernik, M. Anderschitz, G. Colombo, and V. Dietz, "Patient-cooperative strategies for robot-aided treadmill training: first experimental results," IEEE Trans. Neural Systems and Rehabilitation Engineering, vol. 13, no. 3, pp. 380-394, 2005.

[21] R. Riener, L. Lunenburger, I. C. Maier, G. Colombo, and V. Dietz, "Locomotor training in subjects with sensori-motor deficits: An overview of the robotic gait orthosis lokomat," J. Healthcare Engineering, vol. 1, no. 2, pp. 197-216, 2010.

[22] P. O. Riley, G. Paolini, U. D. Croce, and D. Kerrigan, "A kinematic and kinetic comparison of overground and treadmill walking in healthy subjects," Gait and Posture, vol. 26, no. 1, pp. 17-24, 2007.

[23] S. M. Ross, Introductory Statistics. Burlington, MA: Elsevier academic press, 2005.

[24] Y. Stauffer, Y. Allemand, M. Bouri, J. Fournier, R. Clavel, P. Metrailler, R. Brodard, and F. Reynard, "The WalkTrainer-a new generation of walking reeducation device combining orthoses and muscle stimulation," IEEE Trans. Neural Systems and Rehabil Engineering, vol. 17, no. 1, pp. 38-45, 2009.

[25] J. F. Veneman, R. Kruidhof, E. E. G. Hekman, R. Ekkelenkamp, E. H. F. van Asseldonk, and H. van der Kooij, "Design and evaluation of the LOPES exoskeleton robot for interactive gait rehabilitation," IEEE Trans. Neural Systems and Rehabilitation Engineering, vol. 15, no. 3, pp. 379-386, 2007.

[26] A. Wernig and S. Muller, "Laufband locomotion with body weight support improved walking in persons with sever spinal cord injuries," Int. Medical Society of Paraplegia, vol. 30, pp. 229-238, 1992. 